\title{
ANALISIS KESELAMATAN LALU LINTAS JALAN TOL NGAWI-KERTOSONO STUDI KASUS RUAS MADIUN-CARUBAN DAN RUAS CARUBAN-WILANGAN
}

\author{
Beti Irma Sari ${ }^{* 1}$ dan Danny Setiawan ${ }^{2}$ \\ ${ }_{1}^{1}$ Mahasiswa / Program Studi Teknik Sipil / Universitas Teknologi Yogyakarta \\ 2 Dosen / Program Studi Teknik Sipil / Universitas Teknologi Yogyakarta \\ *Korespondensi: betiirmasari@gmail.com
}

\begin{abstract}
Toll roads can reduce travel time to be shorter, easier, more convenient, and smooth. However, many road users neglact safety because it's too comfortable with road conditions that are straight, smooth, and without obstacles. Many road users who drive vehicles exceed the required traffic signs, causing traffic accident. Within 10 months of the operation of the Ngawi-Kertosono toll road on April 1, 2018, until February 24, 2019, traffic accidents reached 59 accidents on the Madiun-Wilangan toll road. From these data, it's necessary to study the causes of toll road traffic accidents in accident-prone areas. As a first step, it's necessary to determine the black site and black spots and the relationship between the geometric factors of the road to reduce the number of traffic accidents on the Madiun-Wilangan toll road. This calculation analysis uses the Z-Score and Cusum method by finding the black spot and black site areas. Based on the results of the analysis there are accidentprone areas on the toll road that is from KM 602 to 622 where the Z-Score is $1.733>0$ and Cusum 7.64>0 so that the accident-prone area can be found on the Black Site and Black Spot results on the road location Madiun, Caruban and Caruban-Wilangan toll road. Suggestions from research need to be conducted outreach or outreach related to traffic and road safety regulations that often have accidents.
\end{abstract}

Keywords : Black Site, Black Spot, Traffic

\section{PENDAHULUAN}

Pembangunan Jalan Tol merupakan usaha pemerintah dalam memudahkan masyarakat Indonesia agar dapat melakukan aktivitas perekonomian maupun sosial dengan baik dan cepat.

Salah satu tol yang menjadi bagian dari Mega Proyek Jalan Tol Trans jawa adalah Jalan Tol Ngawi-Kertosono dengan panjang 87,02 $\mathrm{km}$. Jalan tol dapat memangkas waktu tempuh perjalanan menjadi lebih singkat, mudah, nyaman, dan lancar. Akan tetapi banyak pengguna jalan yang lalai dengan keselamatan karena terlalu nyaman dengan kondisi jalan yang lurus, lancar, dan tanpa hambatan. Banyak pengguna jalan yang memacu kendaraan melebihi batas rambu-rambu yang di syaratkan sehingga menimbulkan kecelakaan lalu lintas.

Dalam kurun waktu 10 bulan sejak beroperasinya jalan tol Ngawi-Kertosono pada tanggal 1 April 2018 sampai dengan 24 Februari 2019, kecelakaan lalu lintas mencapai angka 59 kecelakaan di ruas Madiun-Wilangan [1]. Dari data tersebut maka diperlukan kajian terhadap penyebab kecelakaan lalu lintas jalan tol pada daerah rawan kecelakaan. Sebagai langkah awal perlu menentukan black site dan black spot serta hubungan antara faktor geometrik jalan untuk mengurangi jumlah angka kecelakaan lalu lintas di jalan tol ruas Madiun-Wilangan.

\section{TINJAUAN PUSTAKA}

Hal yang mengakibatkan terganggunya fungsi jalan adalah setiap bentuk tindakan atau 
kegiatan yang dapat mengganggu fungsi jalan, seperti terganggunya jarak atau sudut pandang, timbulnya hambatan samping yang menurunkan kecepatan atau menimbulkan kecelakaan lalulintas, serta terjadinya kerusakan prasarana, bangunan pelengkap, atau perlengkapan jalan [2]. Adapun faktor-faktor penyebab terjadinya kecelakaan diantaranya sebagai berikut:

a. Faktor Kendaraan

Kendaraan merupakan salah satu faktor dalam penyebab terjadinya kecelakaan apabila tidak dikendalikan sebagaimana mestinya. Kondisi teknis sebelum kendaraan digunakan perlu diperhatikan bahwa semua bagian kendaraan dapat berfungsi dengan baik, seperti mesin, rem kemudi, ban, lampu, kaca spion, dan sabuk pengaman [3].

b. Faktor Manusia atau Human Error

Faktor manusia merupakan faktor yang paling dominan terhadap penyebab utama terjadinya kecelakaan. Hampir semua kejadian kecelakaan didahului dengan pelanggaran rambu-rambu lalu lintas. Contoh perilaku pengemudi yang menyebabkan terjadinya kecelakaan yakni kondisi mengantuk dan kelelahan, pandangan dan ketajaman pendengaran, kemampuan membuat keputusan, kecepatan reaksi terhadap perubahan kondisi lingkungan dan jalan [3].

c. Faktor Sarana dan prasarana

Sarana dan prasaran meliputi ketersediaan fasilitas di sepanjang jalan tol, seperti rest area. Bagi pengendara jarak jauh sangat membutuhkan rest area untuk beristirahat sejenak setelah melakukan perjalanan panjang. Karena kondisi fisik yang tidak stabil juga mempengaruhi terjdinya kecelakaan.

d. Faktor Kondisi Lingkungan

Faktor lingkungan merupakan hal yang mempengaruhi terjadinya kecelakaan. Kondisi jalan dan cuaca tertentu dapat menjadi terciptanya keselamatan berkendara dan berlalu lintas. Jalan meliputi bangunan pelengkap dan perlengkapan yang diperuntukkan bagi lalu lintas, yang berada dipermukaan tanah, di atas permukaan tanah, di bawah permukaan tanah dan/atau air, kecuali jalan kereta api, jalan lori dan jalan kabel [2].

Faktor-faktor yang mempengaruhi kondisi lingkungan, yakni lokasi jalan, iklim dan cuaca, volume lalu lintas (karakter arus lalu lintas), dan geometrik jalan [5].

Kecelakaan lalu lintas di jalan disebabkan oleh beberapa faktor, seperti (a) perkerasan jalan yang meliputi, permukaan jalan yang berlubang, licin, dan bergelombang, lebar perkerasan yang tidak memenuhi syarat. (b) pengelolaan jalan yang meliputi, perbaikan jalan yang menyebabkan kerikil dan debu berserakan. (c) alinyemen jalan yang meliputi, tanjakan dan turunan yang terlalu curam dan tajam. (d) rambu-rambu lalu lintas yang meliputi, penempatan rambu yang tidak sesuai standar dan membahayakan pengguna jalan, serta rambu yang rusak. (e) penerangan jalan yang meliputi, lampu penerangan yang rusak dan tidak diganti serta tidak adanya lampu penerangan jalan pada malam hari.

\section{METODOLOGI PENELITIAN}

Penelitian analisis keselamatan lalu-lintas jalan tol Ngawi-Kertosono dilakukan pada ruas Madiun-Wilangan dengan total panjang 29,51 km menggunakan data dari PT.Jasamarga Ngawi Kertosono (PT.JNK) untuk menetukan black spot dan black site. [1]. Lokasi penelitian dapat dilihat pada Gambar 1. (lingkaran berwarna hitam) serta tahapan penelitian pada Gambar 2.

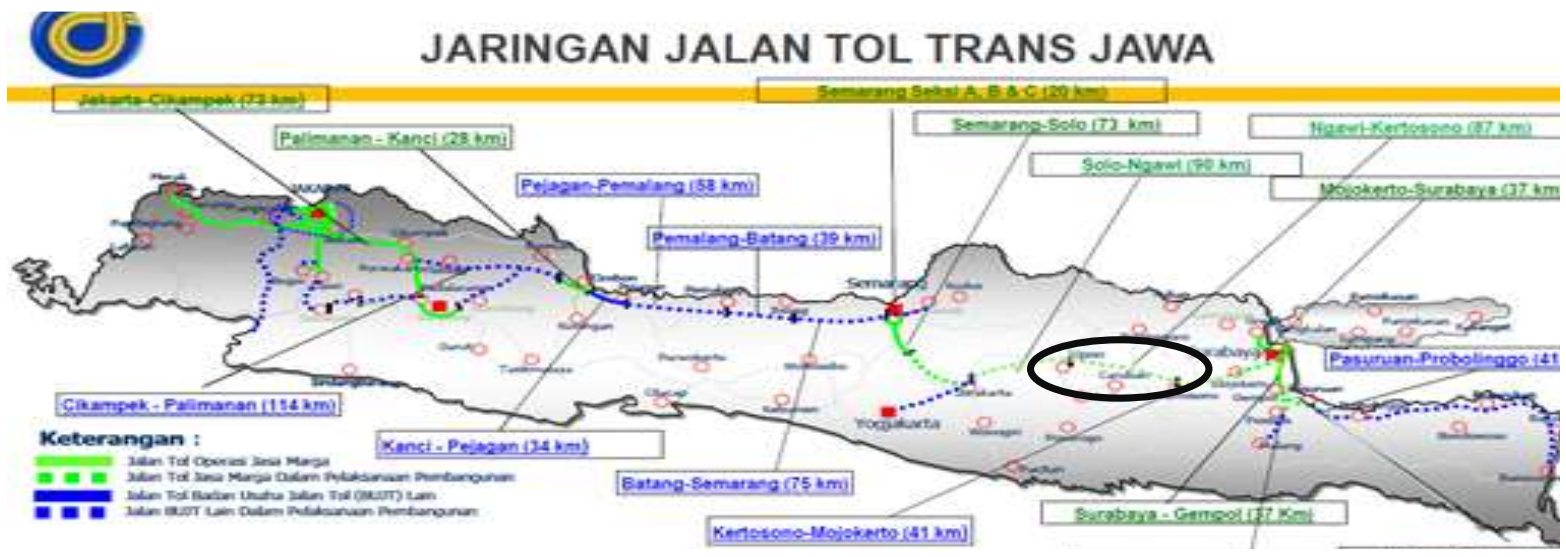

Gambar 1. Peta lokasi jalan tol ruas Madiun-Caruban-Wilangan 


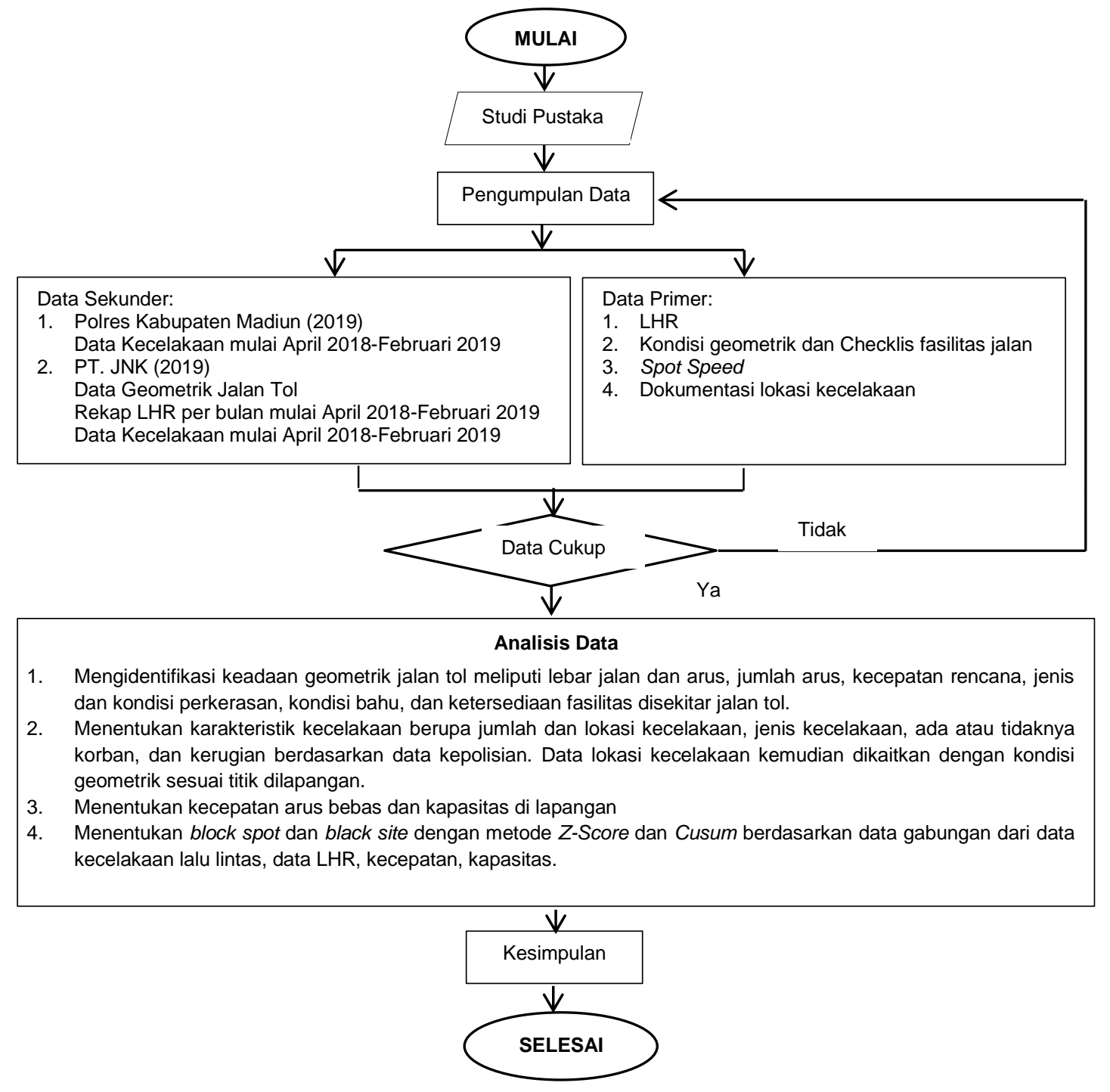

Gambar 2. Diagram alir penelitian

Metode yang digunakan untuk menyelesaikan penelitian adalah metode Cumulative Summary (cusum) untuk black spot dan metode z-score untuk black site setelah itu dilakukan evaluasi perilaku kecelakaan lalu lintas pada daerah rawan kecelakaan dengan tingkat kecelakaan tertinggi di daerah ruas pengamatan.

\section{HASIL DAN PEMBAHASAN 4.1. Geometrik Jalan}

Data geometrik jalan tol berupa gambar penampang atas dan potongan melintang tipikal seperti Gambar 4 [1].

Penelitian dilakukan di ruas Madiun Caruban $(8,45 \mathrm{~km})$ dan Caruban - Wilangan $(21,06 \mathrm{~km})$. Pintu masuk GT Madiun berada di Desa Bagi Kec. Madiun, Kab. Madiun, Jawa
Timur. Pintu masuk Caruban berada di Desa Kuwu Kec. Balerejo, Kab. Madiun, Jawa timur dan pintu masuk Wilangan berada di Desa Petung, Kec. Saradan, Kab. Madiun, Jawa Timur. Adapun gambaran umum lokasi daerah

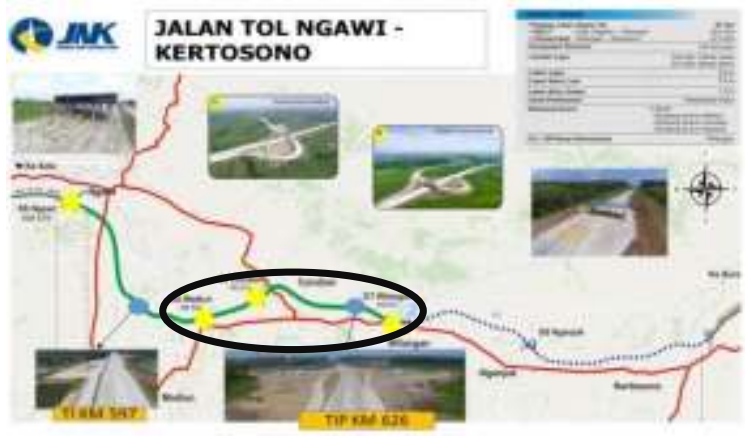

Gambar 3. Peta jalan tol Ngawi-Kertosono (Sumber: PT. JNK, 2019) 
penelitian peta Jalan Tol Ngawi-Kertosono dapat dilihat pada Gambar 3.

Jalan tol ruas Madiun-Wilangan merupakan jalan nasional yang menghubungkan antar ibu kota provinsi. Panjang jalan tol Ngawi-Kertosono sepanjang 87,02 km. Lebar jalan tol memiliki total lebar 24,2 m (4/2D).

Ruas yang ditinjau pada ruas MadiunCaruban memiliki panjang $8,45 \mathrm{~km}$ dan ruas
Caruban-Wilangan sepanjang 21,06 km. perencanaan jalan tol dibuat menjadi dua jenis, yakni untuk daerah timbunan dan daerah galian. Median jalan merupakan suatu pemisah fisik jalur lalu lintas yang berfungsi untuk mengurangi cahaya lampu dari kendaraan berlawan arah. Adapun detail penampang melintang dapat dilihat pada Gambar 4.



Gambar 4. Penampang melintang jalan tol daerah timbunan

\subsection{Data Kecelakaan Lalu Lintas Jalan Tol \\ 4.2.1 Volume Lalu Lintas Harian}

Berdasarkan hasil survei kinerja lalu lintas jalan tol ruas Madiun-Wilangan didapatkan volume lalu lintas harian rata-rata.
Arus puncak kendaraan yang melintas di jalan tol Ruas Madiun-Wilangan terjadi pada hari sabtu dengan total kendaraan mencapai 4846 kendaraan dan kepadatan arus terjadi mulai pukul 16.00 WIB dapat dilihat pada Gambar 5.

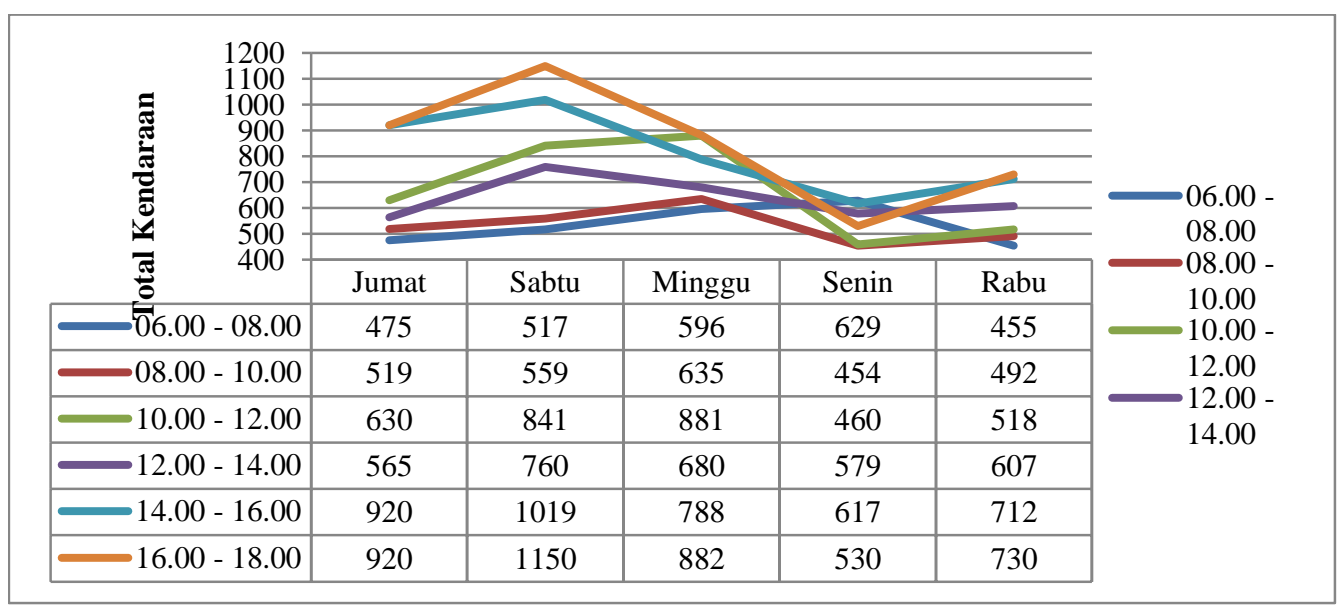

Gambar 5. Rekapitulasi jumlah kendaraan

\subsubsection{Volume Lalu Lintas Harian}

Tabel 1. Klasifikasi waktu kecelakaan

\begin{tabular}{c|c|c}
\hline Klasifikasi & Waktu & Jumlah kejadian \\
\hline Pagi hari & $04.00-10.00$ & 13 \\
\hline Siang hari & $10.00-15.00$ & 14 \\
\hline Sore hari & $15.00-19.00$ & 13 \\
\hline Malam hari & $19.00-04.00$ & 19 \\
\hline \multicolumn{2}{c}{ Total } & 59 \\
\hline
\end{tabular}

Berdasarkan Tabel 1, tingkat seringnya terjadi kecelakaan pada waktu pagi hari (pukul 04.00-10.00 WIB) sebesar 13 kejadian atau $22 \%$, siang hari (pukul 10.00-15.00 WIB) sebesar 14 kejadian atau $23,7 \%$, sore hari (pukul 15.00-19.00 WIB) sebesar 13 kejadian atau $22 \%$, dan malam hari (pukul 19.00-04.00 WIB) sebesar 19 kejadian atau 32,2\%.

Dapat disimpulkan bahwa pada kondisi malam hari adalah waktu rawan terjadinya 
kecelakaan lalu lintas di jalan tol.

\subsubsection{Penyebab Kecelakaan}

Adapun penyebab terjadinya kecelakaan lalu lintas jalan tol paling tinggi diakibatkan karena mengantuk (human error) sebesar $45,8 \%$, ban pecah sebesar $23,7 \%$, kurang antisipasi sebesar $11,9 \%$, selip ban sebesar $8,5 \%$, lengah sebesar $3,4 \%$, kecepatan tinggi, rem blong, patah pelek roda, dan genangan air sebesar 1,7\%. (Lihat Gambar 6).

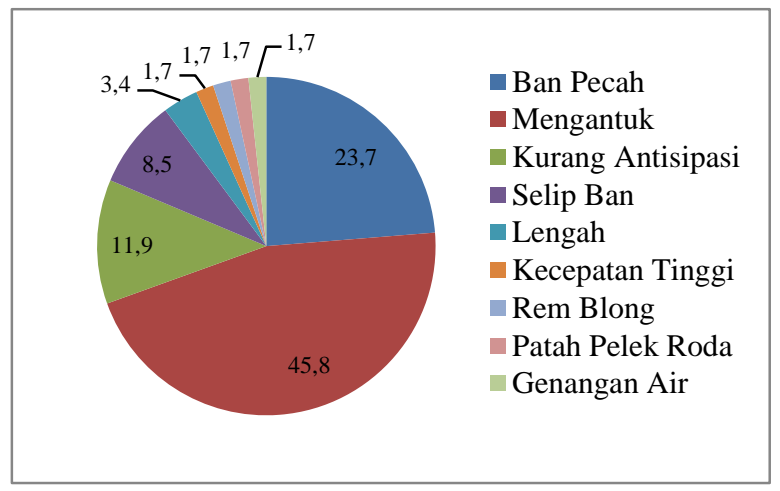

Gambar 6. Penyebab kecelakaan

\subsubsection{Dampak Kecelakaan}

Tabel 2. Dampak terjadinya kecelakaan

\begin{tabular}{c|l|c|c|c}
\hline No & \multicolumn{1}{|c|}{ Bulan/Tahun } & $\begin{array}{c}\text { Korban } \\
\text { Ringan }\end{array}$ & $\begin{array}{c}\text { Korban } \\
\text { Berat }\end{array}$ & $\begin{array}{c}\text { Korban } \\
\text { Meninggal }\end{array}$ \\
\hline 1 & Apr-18 & 13 & 3 & - \\
\hline 2 & Mei-18 & - & - & - \\
\hline 3 & Jun-18 & 8 & 3 & - \\
\hline 4 & Jul-18 & 4 & 3 & 1 \\
\hline 5 & Agust-18 & 4 & 1 & 1 \\
\hline 6 & Sep-18 & 1 & - & - \\
\hline 7 & Okt-18 & 1 & - & - \\
\hline 8 & Nov-18 & 2 & 1 & - \\
\hline 9 & Des-18 & 14 & 6 & 1 \\
\hline 10 & Jan-19 & 3 & 2 & 2 \\
\hline 11 & Feb-19 & 7 & 3 & 2 \\
\hline & Jumlah & 57 & 22 & 7 \\
\hline
\end{tabular}

Dampak terbesar terjadinya kecelakaan lalu lintas jalan tol mengakibatkan luka ringan dengan jumlah korban mencapai 57 orang atau sebesar $66,3 \%$, luka berat sebanyak 22 orang atau sebesar $25,6 \%$, dan meninggal dunia sebanyak 7 orang atau sebesar $8,1 \%$.

\subsection{Analisis Data}

\subsubsection{Kecepatan Arus Bebas}

Persamaan untuk menentukan kecepatan arus bebas adalah sebagai berikut:

$$
\mathrm{FV}=\mathrm{FV}_{\mathrm{o}}+\mathrm{FV}_{\mathrm{w}}
$$

Keterangan:

FV =Kecepatan arus bebas pada kondisi lapangan $(\mathrm{km} / \mathrm{jam})$

$\mathrm{FV}_{\mathrm{o}}=$ Kecepatan arus bebas dasar $(\mathrm{km} / \mathrm{jam})$

$\mathrm{FV}_{\mathrm{w}}=$ Penyesuaian untuk lebar efektif jalur lalu lintas $(\mathrm{km} / \mathrm{jam})$

Berdasarkan hasil perhitungan dengan menggunakan persamaan 1 didapatkan kecepatan arus bebas pada ruas jalan tol Madiun-Wilangan pada kondisi lapangan untuk kendaraan ringan (LV) sebesar 89,2 km/jam, kendaraan berat menengah (MHV) sebesar 71,2 $\mathrm{km} / \mathrm{jam}$, truk besar (LT) sebesar $66,2 \mathrm{~km} / \mathrm{jam}$, dan bus besar sebesar (LB) $91,2 \mathrm{~km} / \mathrm{jam}$.

\subsubsection{Spot Speed}

Persamaan untuk menentukan spot speed adalah sebagai berikut:

$$
\mathrm{K}=\frac{3,6 \times \mathrm{J}}{\mathrm{W}}
$$

Keterangan:

$\mathrm{K}=$ Kecepatan sesaat $(\mathrm{km} / \mathrm{jam})$

$\mathrm{J}=$ Panjang jalan $(\mathrm{m})$

$\mathrm{W}=$ Waktu tempuh (detik)

Berdasarkan hasil perhitungan dengan menggunakan persamaan 2 didapatkan spot speed pada ruas jalan tol Madiun-Wilangan untuk kendaraan ringan (LV) sebesar 180 $\mathrm{km} / \mathrm{jam}$, kendaraan berat menengah (MHV) sebesar $120 \mathrm{~km} / \mathrm{jam}$, truk besar (LT) sebesar 72 $\mathrm{km} / \mathrm{jam}$, dan bus besar (LB) sebesar $40 \mathrm{~km} / \mathrm{jam}$.

\subsubsection{Kapasitas Jalan Bebas Hambatan}

Kapasitas sebagai arus lalu lintas maksimum yang dapat didukung pada ruas jalan atau persimpangan pada keadaan tertentu[6].

Persamaan untuk menentukan kapasitas jalan bebas hambatan adalah sebagai berikut:

$$
\mathrm{C}=\mathrm{C}_{\mathrm{O}} \times \mathrm{FC}_{\mathrm{W}} \times \mathrm{FC}_{\mathrm{SP}}
$$

Keterangan:

$\mathrm{C} \quad=$ Kapasitas $(\mathrm{smp} / \mathrm{jam})$

$\mathrm{C}_{\mathrm{O}}=$ Kapasitas dasar

$\mathrm{FC}_{\mathrm{W}}=$ Faktor penyesuaian akibat lebar jalur lalu lintas

$\mathrm{FC}_{\mathrm{SP}}=$ Faktor penyesuaian akibat pemisah arah

(jalan bebas hambatan tak terbagi)

Berdasarkan perhitungan kapasitas ruas jalan bebas hambatan sebesar 2300 smp/jam/lajur. Untuk tipe alinyemen datar empat lajur dua arah terbagi (4/2D) maka kapasitas total $9200 \mathrm{smp} / \mathrm{jam}$.

\subsubsection{Jarak Pandang Henti}

Persamaan untuk menentukan jarak pandang henti adalah sebagai berikut:

$$
J P H=0,278 \times V_{R} \times T+\frac{V^{2}}{254 \times f}
$$


Berdasarkan perhitungan didapat nilai jarak pandang sebesar $84,65 \mathrm{~m}$. Nilai tersebut memenuhi standar Bina Marga 1998 untuk kecepatan rencana $60 \mathrm{~km} / \mathrm{jam}$.

\subsubsection{Karakteristik Daerah Rawan Kecelakaan}

Karakteristik daerah rawan kecelakaan lalu lintas di jalan tol Ruas Madiun-Wilangan dipengaruhi oleh kejadian kecelakaan yang melibatkan manusia dengan kendaraan, kondisi jalan, volume kendaraan, kapasitas jalan, dan geometrik jalan.

a. Peristiwa Kejadian Kecelakaan Lalu Lintas

Berdasarkan Tabel 1, lokasi terjadinya kecelakaan tertinggi terletak pada KM 604 s/d 605 dengan jumlah angkan kecelakaan sebesar 7 kejadian, KM 610 s/d 611 dan KM 621 s/d 622 angka kecelakaan sebesar 6 kejadian, KM 620 s/d 621 angka kecelakaan sebesar 5 kejadian.

b. Rambu Lalu Lintas

Berdasarkan hasil survei dilapangan pada ruas tol Madiun-Wilangan dapat diketahui kondisi rambu-rambu lalu lintas jalan tol sebagai berikut:

1. Ruas Madiun-Caruban

Ruas jalan tol dengan panjang $8,45 \mathrm{~km}$ memiliki rambu-rambu lalu lintas yang belum memadai terutama lampu penerangan di sepanjang jalan tol. Lampu penerangan hanya berada pada interchange.

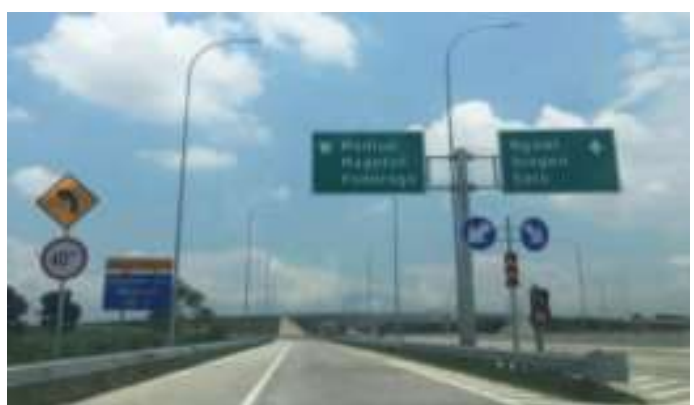

Gambar 7. Rambu lalu lintas

2. Ruas Caruban-Wilangan

Ruas jalan tol dengan panjang 21,06 km memiliki rambu-rambu lalu lintas yang belum cukup memadai terutama lampu penerangan di sepanjang jalan tol. Lampu penerangan hanya berada pada interchange dan terpasang padajarak $1 \mathrm{~km}$ sebelum memasuki jalan tol dan sesudah jalan tol.

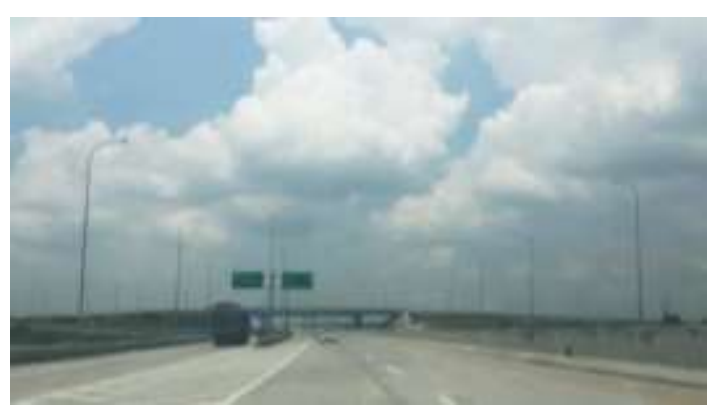

Gambar 8. Fasilitas lampu penerangan di Interchange

c. Volume Kendaraan dan Satuan Mobil Penumpang

Volume kendaraan di jalan tol terdiri atas LV, MHV, LB, dan LT.

Berdasarkan Gambar 5 diperoleh volume lalu lintas, tingkat kendaraan yang melintas tertinggi pada hari Sabtu dengan total 4846 kendaraan yang dikonversi sebesar 5011 SMP/Jam dan didominasi oleh kendaran ringan (LV) sebesar 92,36\%, kendaraan berat menengah (MHV) sebesar 4,25\%, bus besar (LB) sebesar $2,51 \%$, dan truk besar (LT) sebesar $0,86 \%$. Pengamatan dilaksanakan mulai pukul 06.00-18.00 WIB. Lonjakan kenaikan kendaraan yang melintas di jalan tol terjadi mulai pukul 16.00-18.00 WIB.

\subsubsection{Analisis Z-Score untuk Black Site}

Menentukan black site menggunakan metode $z$-score untuk mengetahui tingkat pertumbuhan rata-rata kejadian kecelakaan[7].

a. Mencari Nilai Rata-Rata Data

Nilai rata-rata $\mathrm{x}$ adalah jumlah angka kecelakaan mulai Bulan April 2018 sampai Bulan Februari 2019 dibagi dengan jumlah data, dimana angka kecelakaan 57 kejadian dan jumlah data 17 lokasi kejadian.

$$
\mathrm{X}=\frac{\Sigma \mathrm{x}}{\mathrm{n}}=\frac{57}{17}=3,35
$$

b. Mencari Nilai Standar Deviasi

Nilai standar deviasi (S) adalah akar dari jumlah kuadrat rata-rata angka kecelakaan mulai Bulan April 2018 sampai Bulan Februari 2019 dikurangi rata-rata angka kecelakaan dibagi dengan jumlah data.

$$
\mathrm{S}=\sqrt{\frac{\sum(\mathrm{x}-\mathrm{x})^{2}}{\mathrm{n}}}=\sqrt{\frac{159,26}{17}}=2,1
$$


c. Mencari Nilai $\mathrm{Z}_{\mathrm{i}}$

Nilai Z-Score adalah rata-rata angka kecelakaan per tahun dikurangi angka kecelakaan dibagi standar deviasi, dimana dalam contoh perhitungan diambil ruas jalan Caruban-Wilangan KM 610 s/d 611 dengan nilai rata-rata jumlah kecelakaan 6 kejadian, nilai rata-rata kecelakaan sebesar 3,35, dan nilai standar deviasi sebesar 2,10.

Tabel 3. Hasil Analisis Z-Score untuk

\begin{tabular}{|c|c|c|c|c|}
\hline $\begin{array}{c}\text { Nama Ruas } \\
(\mathrm{KM})\end{array}$ & $\begin{array}{c}\text { Jumlah } \\
\text { Kecelakaan }\end{array}$ & $\mathrm{Z}$ & Kelas & Keterangan \\
\hline $602 \mathrm{~s} / \mathrm{d} 603$ & 3 & $-0,17$ & & Tidak Rawan Kecelakaan \\
\hline $604 \mathrm{~s} / \mathrm{d} 605$ & 7 & 1,73 & I & $\begin{array}{l}\text { Rawan Kecelakaan } \\
\text { Sangat Tinggi }\end{array}$ \\
\hline $605 \mathrm{~s} / \mathrm{d} 606$ & 2 & $-0,64$ & & Tidak Rawan Kecelakaan \\
\hline $606 \mathrm{~s} / \mathrm{d} 607$ & 3 & $-0,17$ & & Tidak Rawan Kecelakaan \\
\hline $607 \mathrm{~s} / \mathrm{d} 608$ & 3 & $-0,17$ & & Tidak Rawan Kecelakaan \\
\hline 608 s/d 609 & 4 & 0,31 & III & $\begin{array}{ll}\text { Rawan } & \text { Kecelakaan } \\
\text { Rendah } & \\
\end{array}$ \\
\hline $610 \mathrm{~s} / \mathrm{d} 611$ & 6 & 1,26 & I & $\begin{array}{l}\text { Rawan Kecelakaan } \\
\text { Sangat Tinggi }\end{array}$ \\
\hline $611 \mathrm{~s} / \mathrm{d} 612$ & 2 & $-0,64$ & & Tidak Rawan Kecelakaan \\
\hline $612 \mathrm{~s} / \mathrm{d} 613$ & 2 & $-0,64$ & & Tidak Rawan Kecelakaan \\
\hline $614 \mathrm{~s} / \mathrm{d} 615$ & 2 & $-0,64$ & & Tidak Rawan Kecelakaan \\
\hline $615 \mathrm{~s} / \mathrm{d} 616$ & 2 & $-0,64$ & & Tidak Rawan Kecelakaan \\
\hline $616 \mathrm{~s} / \mathrm{d} 617$ & 2 & $-0,64$ & & Tidak Rawan Kecelakaan \\
\hline $617 \mathrm{~s} / \mathrm{d} 618$ & 3 & $-0,17$ & & Tidak Rawan Kecelakaan \\
\hline $618 \mathrm{~s} / \mathrm{d} 619$ & 2 & $-0,64$ & & Tidak Rawan Kecelakaan \\
\hline $619 \mathrm{~s} / \mathrm{d} 620$ & 3 & $-0,17$ & & Tidak Rawan Kecelakaan \\
\hline $620 \mathrm{~s} / \mathrm{d} 621$ & 5 & 0,78 & II & $\begin{array}{ll}\text { Rawan } & \text { Kecelakaan } \\
\text { Tinggi }\end{array}$ \\
\hline $621 \mathrm{~s} / \mathrm{d} 622$ & 6 & 1,26 & I & $\begin{array}{l}\text { Rawan Kecelakaan } \\
\text { Sangat Tinggi }\end{array}$ \\
\hline Jumlah & 57 & & & \\
\hline Rata-Rata & 3,35 & & & \\
\hline $\begin{array}{r}\text { Standar } \\
\text { Deviasi (S) }\end{array}$ & 2,10 & & & \\
\hline
\end{tabular}

Berdasarkan Tabel 3 diketahui kriteria rawan kecelakaan pada Ruas Madiun-Wilangan, meliputi sangat tinggi, tinggi, rendah, dan tidak rawan kecelakaan. Adapun ruas jalan tol tersebut antara lain, KM 604 s/d 605 dengan kriteria rawan kecelakaan sangat tinggi dan memiliki nilai $Z$-Score sebesar 1,73

\subsubsection{Analisis Cusum untuk Black Spot}

Cusum untuk mendeteksi perubahan kecil dari nilai mean, kemudian hasil perhitungan dibuat grafik untuk memudahkan dalam mendeteksi titik ruas jalan tol yang sering terjadi kecelakaan dan rawan kecelakaan.

\section{a. Mencari Nilai Mean (W)}

Nilai mean adalah jumlah kecelakaan dibagi dengan junlah stasioning dikali waktu, dimana perhitungan ini diambil ruas jalan tol Madiun-Caruban KM 604 s/d 605 sebanyak 7 kecelakaan, jumlah stasion sebanyak 2, dan waktu selama 0,92 tahun/11 bulan.

$$
\mathrm{W}=\frac{\Sigma \mathrm{X}_{1}}{\mathrm{~L} \times \mathrm{T}}=\frac{7}{2 \times 0,92}=3,82
$$

b. Mencari Nilai Cusum Kecelakaan Tahun Pertama $\left(\mathrm{S}_{\mathrm{o}}\right)$

Nilai cusum kecelakaan bulan pertama pada stasion pertama di KM 604 s/d 605 sebanyak 7 kejadian dan nilai mean 3,82 .

$$
S_{o}=\left(\mathrm{X}_{1}-\mathrm{W}\right)=(7-3,82)=3,18
$$

c. Mencari Nilai Cusum Kecelakaan Tahun Selanjutnya $\left(\mathrm{S}_{1}\right)$

Nilai cusum kecelakaan bulan selanjutnya adalah nilai cusum kecelakaan bulan pertama ditambah dengan jumlah kecelakaan dikurangi nilai mean, dimana nilai cusum kecelakaan bulan pertama 3,18. Kemudian jumlah kecelakaan bulan pertama pada stasion pertama sebesar 7 kejadian dengan nilai mean 3,82.

Tabel 4. Hasil Analisis Cusum untuk (Black Spot)

\begin{tabular}{c|l|c|l}
\hline No & \multicolumn{1}{|c|}{$\begin{array}{c}\text { Nama Ruas } \\
\text { KM }\end{array}$} & C & \multicolumn{1}{|c}{ Kriteria } \\
\hline 1 & Madiun-Caruban & & \\
\hline 2 & KM 604 s/d 605 608 s/d 609 & 6,36 & $\begin{array}{l}\text { Rawan Kecelakaan Sangat } \\
\text { Tinggi }\end{array}$ \\
\hline & Caruban-Wilangan & & Rawan Kecelakaan Rendah \\
\hline 1 & KM 610 s/d 611 & 7,64 & $\begin{array}{l}\text { Rawan Kecelakaan Sangat } \\
\text { Tinggi }\end{array}$ \\
\hline 2 & KM 620 s/d 621 & 6,36 & Rawan Kecelakaan Tinggi \\
\hline 3 & KM 621 s/d 622 & 7,64 & $\begin{array}{l}\text { Rawan Kecelakaan Sangat } \\
\text { Tinggi }\end{array}$ \\
\hline
\end{tabular}

Berdasarkan Tabel 4 diketahui titik rawan kecelakaan yakni ruas Madiun-Caruban pada KM 604 s/d 605 dengan nilai cusum 6,36, sedangkan untuk ruas Caruban-Wilangan pada KM 610 s/d 611 dan KM 620 s/d 621 dengan nilai cusum 7,64.Analisis Black Spot pada ruas Madiun-Caruban dapat dilihat pada Gambar 9 dan Gambar 10.

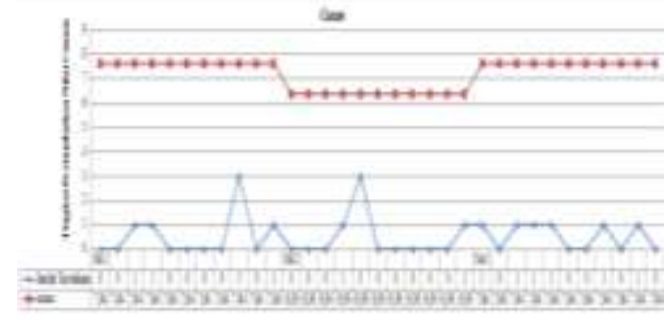

Gambar 9. Black Spot pada ruas MadiunCaruban

Analisis Black Spot pada ruas Caruban Wilangan dapat dilihat pada Gambar 11. 


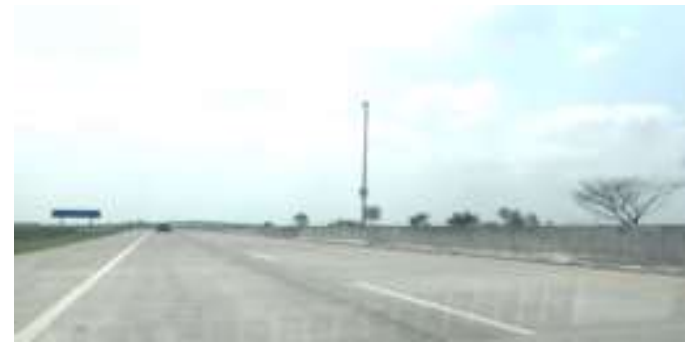

Gambar 10. KM 604 s/d 605

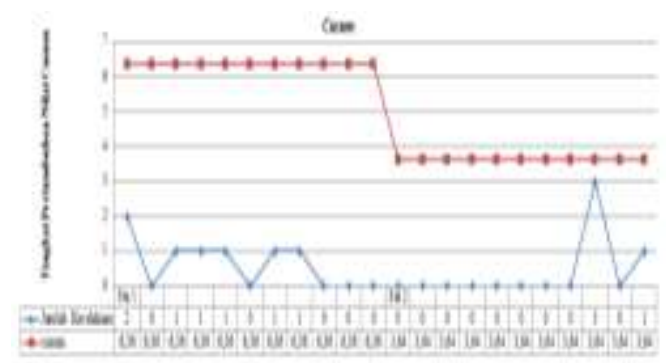

Gambar 11. Black Spot pada ruas CarubanWilangan

Berdasarkan hasil analisis, ruas MadiunCaruban yang teridentifikasi sebagai kriteria rawan kecelakaan tinggi pada KM 604 s/d 605 dengan nilai $z$-score 1,73 . Sedangkan untuk titik rawan kecelakaan memiliki nilai cusum sebesar 6,36 .

Ruas Caruban - Wilangan yang teridentifikasi sebagai kriteria rawan kecelakaan tinggi pada KM 610 s/d 611 dan KM 621 s/d 622 dengan nilai $z$-score 1,26 . Sedangkan untuk titik rawan kecelakaan memiliki nilai cusum sebesar 6,36 .

Berdasarkan faktor penyebab kecelakaan tertinggi akibat mengantuk dan kurangnya antisipasi saat berkendara. Kecepatan pengendara yang mlebihi standar kecepatan yakni antara 60-100 km/jam beresiko mengalami kecelakaan.

Dapat disimpulkan bahwa kondisi geometrik jalan tol bukan menjadi penyebab terjadinya kecelakaan lalu lintas jalan tol.

Upaya pencegahan kecelakaan lalu lintas yang dapat diterapkan di jalan tol ruas MadiunWilangan adalah sebagai berikut:

a. Garis kejut atau pita penggaduh

Pita penggaduh berfungsi untuk membuat pengemudi lebih meningkatkan kewaspadaan menjelang lokasi yang berpotensi terjadinya kecelakaan lalu lintas yakni pada titik rawan kecelakaan KM 604 s/d 605, KM 610 s/d 611, dan KM $621 \mathrm{~s} / \mathrm{d} 622$.
b. Warning Light
Warning light berkedip sesuai dengan

kebutuhan di lapangan sehingga dapat mengundang perhatian pengemudi agar berhatihati saat berkendara. Penempatan warning light disesuaikan dengan daerah kebutuhannya dan dilengakapi dengan pemasangan pita penggaduh. c. Smart CCTV

Pemasangan smart CCTV tol dipasang minimal setiap satu kilometer untuk lebih mengetahui kondisi dan lalu lintas di jalan tol. Salah satu peristiwa yang sering terjadi yakni kecelakaan lalu lintas.

d. Rambu Kecepatan

Rambu informasi area pengawasan oleh CCTV yang akan dipasang pada jarak $1 \mathrm{KM}$ sebelum lokasi pemasangan smart CCTV. Rambu-rambu informasi berfungsi agar pengemudi selalu berhati-hati dalam berkendarn dan mengurangi kecepatan kendaraannya.

e. Rest area di KM 610 s/d 623

Edukasi terhadap pengemudi pengguna tol perlu digalakkan. Jalan tol yang nyaman dapat mengakibatkan micro sleep yang dapat terjadi sekitar empat hingga lima detik yang jika terjadi kecelakaan bisa fatal. Setiap dua hingga tiga jam berkendara di jalan tol, pengemudi harus beristirahat di rest area.

f. Jalankan program 3E

Program 3E (education, enforcement, engineering) perlu dilakukan untuk antisipasi dini mencegah kasus kecelakaan agar tidak terjadi kembali. Education dengan sosialisasi keselamatan dan kamtibnas untuk warga sekitar tol. Ada sosialisasi dengan flyer, spanduk, vms, dan videotron. Enforcement dengan bekerjasama dengan kewilayahan pihak Dinas Perhubungan mengadakan operasi speed gun dan ODOL (overdimensi dan overloading). Selain itu setiap bulan dilakukan evaluasi penyebab lakalantas. Engineering dengan penambahan wirerope, guardrail, dan perkerasan permukaan jalan.

\section{KESIMPULAN}

\subsection{Kesimpulan}

Berdasarkan penelitian yang telah dilakukan, maka dapat ditarik kesimpulan sebagai berikut:

a. Lokasi rawan kecelakaan dan titik rawan kecelakaan di jalan tol ruas MadiunWilangan, sebagai berikut:

1. Analisis Z-Score untuk identifikasi daerah rawan kecelakaan (black site) dengan kriteria daerah rawan kecelakaan sangat tinggi berada di lokasi KM 604 
s/d 605, KM 610 s/d 622, dan KM 621 s/d 622, kriteria rawan kecelakaan rendah pada KM 608 s/d 609.

2. Analisis Cusum untuk titik rawan kecelakaan (black spot) dengan kriteria rawan kecelakaan sangat tinggi berlokasi di KM 604 s/d 605, KM 610 s/d 611, KM 620 s/d 621, dan KM 621 s/d 622, sedangkan kriteria rawan kecelakaan rendah pada KM 608 s/d 609.

b. Penyebab terjadinya kecelakaan lalu lintas di jalan tol ruas Madiun-Wilangan akibat human error, yakni mengantuk dan kurang antisipasi. Solusi untuk mengurangi tingkat kecelakaan adalah dengan kelengkapan fasilitas jalan tol, seperti lampu penenrangan jalan, rest area di ruas Caruban-Wilangan, pemasangan videotron di rest area tentang keselamatan lalu lintas hingga dampak terjadinya keelakaan sehingga meningkatkan kewaspadaan pengendara.

\section{DAFTAR PUSTAKA}

[1] PT. Jasamarga Ngawi Kertosono (JNK), (2019). Rekapitulasi Data Kecelakaan Lalu Lintas Jalan Tol Ngawi-Kertosono, Gambar Tipikal Potongan Melintang, Rekap Data Lalu Lintas Harian Bulanan, Madiun.

[2] Undang-undang Republik Indonesia Nomor 38 Tahun 2004 Tentang Jalan.

[3] Purnomo, (2011), Hubungan Faktor Personal Dengan Tindakan Mengemudi Agresif Pada Pengemudi Truk Pengangkut Produk, Skripsi, Fakultas Kesehatan Masyarakat, Universitas Diponegoro, Semarang.

[4] Kartika, M., (2009), Analisis Faktor Penyebab Kecelakaan Lalu Lintas Pada Pengendara Sepeda Motor Di Wilayah Depok, Fakultas Kesehatan Masyarakat, Universitas Indonesia, Jakarta.

[5] Oglesby dan Hick, (1999), Perencanaan Transportasi dan Manajemen Transportasi, Bummu Media, Jakarta.

[6] Direktorat Jendral Bina Marga, (1997), Manual Kapasitas Jalan Indonesia), Departemen Pekerjaan Umum.

[7] Hasan I., (2001), Kajian Lalu Lintas dan Analisis Jalan, Universitas Gajah Mada, Yogyakarta. 